\title{
Anemia in Patients with Diabetes Mellitus: Prevalence and Progression
}

Al-Salman $\mathbf{M}^{*}$

Department of Internal Medicine, King Faisal University, Hofuf, Saudi Arabia

*Corresponding author: Mortadah Al-Salman, MBBS, MD, Department of Internal Medicine, King Faisal University, Hofuf, Saudi Arabia, Tel: 966506914993; E-mail: Mortadah@hotmail.com

Rec date: Jan 03, 2015 Acc date: Feb 10, 2015 Pub date: Feb 15, 2015

Copyright: (C) 2015 Al-Salman M. This is an open-access article distributed under the terms of the Creative Commons Attribution License, which permits unrestricted use, distribution, and reproduction in any medium, provided the original author and source are credited.

\section{Abstract}

Aim: Anemia is found to contribute to the development and progression of micro and macro-vascular complications of diabetes. This study aimed to determine the prevalence of anemia in patients with diabetes and the occurrence of micro and macro vascular complications in them.

Method: This was a retrospective study of 227 Saudi patients with diabetes regularly followed up as outpatients for one year. Patient's demographic profile, history of stroke, ischemic heart disease (IHD), and concomitant hypertension (HT) along with the most recent values of complete blood picture and renal function tests were collected from the database of the health center.

Results: The prevalence of anemia in our study population is $55.5 \%$, which is two to three times more common as compared to the result from previous studies. Anemia was six times more common (53.9\%) compared to the previous study for the same GFR value (GFR > $60 \mathrm{~mL} / \mathrm{min} / 1.73 \mathrm{~m}^{2}$ ) and half of them in stage one kidney disease.

Conclusion: Anemia is a common accompaniment with diabetes and it is seen early even in the absence of renal impairment which necessitate early screening of anemia and further studies to know the possible etiology.

Keywords: Diabetes; Anemia; Prevalence

\section{Introduction}

Diabetes is a major public health problem worldwide. Globally it is estimated that 382 million people suffer from diabetes with a prevalence of $8.3 \%$. Saudi Arabia with a prevalence of $(23.9 \%)$, is one of the top 10 countries with higher prevalence of diabetes [1].

Several studies suggest that anemia is twice as common in diabetics compared with non-diabetics [2]. Despite these facts, anemia is unrecognized in $25 \%$ of the diabetic patients [3]. Anemia also develops earlier and is more severe in patients with diabetes than in patients with renal impairment from other causes [4]. Additionally, the risk of anemia is higher in people with diabetic nephropathy compared with people with nephropathy from other causes and is associated with a more rapid decline in the GFR [5,6]. However, it develops whilst serum creatinine is within the normal range in $5 \%$ of the cases [5]. Recent studies have linked anemia with relatively low serum erythropoietin in persons with either type 1 or type 2 diabetes, even without advanced kidney disease or overt uremia [7]. The etiology of anemia in diabetes is multifactorial and includes inflammation, nutritional deficiencies, concomitant autoimmune diseases, drugs, and hormonal changes in addition to kidney disease [3]. Anemia is found to contribute to the development and progression of micro- and macro-vascular complications of diabetes, which has a negative impact on the quality of life and an additional burden on the health of the patients $[4,8]$. It is therefore important to diagnose and correct anemia among diabetic patients early. 6 This study aimed to determine the prevalence of anemia in diabetics and the occurrence of micro and macro vascular complications in them.

\section{Material and Methods}

This was a retrospective study of Saudi diabetic patients regularly followed up as outpatients at the primary health center attached to King Faisal University, Al Ahsa. Data was collected with the approval of Health center's ethics committee.

\section{Subjects}

All diabetic patients attending the Out Patient Department between 1st January 2010 and 31st December 2011, were included in the study evaluation.

\section{Determination of variables}

Patient's demographic profile, history of stroke, ischemic heart disease (IHD), and concomitant hypertension (HT) along with complete blood picture and renal function tests were collected from the database of the health center. The most recent values were used for the analysis. Estimated glomerular filtration rate (GFR) using Chronic Kidney Disease Epidemiology Collaboration (CKD-EPI) equation formula was used to define renal failure.

\section{Definition of Diabetes}

Diabetes was diagnosed, when the fasting glucose value was $>125$ $\mathrm{mg} / \mathrm{dL}$, or random blood glucose $>200 \mathrm{mg} / \mathrm{dL}$ or patients on treatment for diabetes. The diagnosis of diabetes was based on the "Definition and description of diabetes mellitus" from American Diabetes Association 2010 [9]. 
Page 2 of 4

\section{Anemia}

Was considered as per the World Health Organization's genderspecific criteria, $(<13 \mathrm{~g} / \mathrm{dL}$ in men and $<12 \mathrm{~g} / \mathrm{dL}$ in women) [10]. Anemia was defined as normocytic with a mean corpuscular volume $(\mathrm{MCV})$ of 80 to $100 \mathrm{FL}$, microcytic with the $\mathrm{MCV}<80 \mathrm{FL}$, and macrocytic with the MCV $>100$ FL [11]

\section{Renal failure}

Patients were classified based on estimated glomerular filtration rate (EGFR). EGFR values $<90 \mathrm{~mL} / \mathrm{min} / 1.73 \mathrm{~m}^{2}$ were considered abnormal (CKD 2-5). Staging of CKD was based on the Kidney Disease Outcomes Quality Initiative (K/DOQI) guidelines: $\geq 90$ (CKD1), 60-89 (CKD2), 30-59 (CKD3), 15-29 (CKD4) and <15 (CKD5) $\mathrm{ml} / \mathrm{min} 1.73 \mathrm{~m}^{2}$. Creatinine clearance (CCr) was determined using the (CKD-EPI) equation formula to define renal failure [12-14]

\section{Statistical analysis}

Descriptive analysis were used to characterize the study sample by demographics, including sex, age, prevalence of hypertension, stroke, heart disease in relation to anemia and kidney function. The result was presented in the form of tables, using frequencies percentage, mean and standard deviation to describe the study sample in relation to relevant variables. P-value less than 0.05 was taken as statistical significant. Chi-square statistics was used for testing the association between the categorical variables. All the data were manually checked for its clarity and completeness, then coded, entered and transported to IBM SPSS version 22.0 software package for analysis.

\section{Results}

\section{Study groups}

Two hundred and twenty seven diabetic patients were evaluated, $112(49.3 \%)$ were men and 115 (50.7\%) were women. Mean age of the patients was $57.8 \pm 17.1$. Clinical characteristics of the patients were shown in Table 1.

\begin{tabular}{|l|l|l|}
\hline & Frequency & Percentage (\%) \\
\hline \multirow{2}{*}{ Gender } & Male 112 & 40.9 \\
\cline { 2 - 3 } & Female 115 & 50.7 \\
\hline Age & $57.8 \pm 17.1$ & \\
\hline Heart disease & 138 & 60.8 \\
\hline Stroke & 50 & 22 \\
\hline Renal replacement therapy & 6 & 15 \\
\hline
\end{tabular}

Table 1: Characteristics of Study Participants. Mean \pm standard deviation (SD)

\section{Prevalence}

Of the 227 patients with diabetes, $126(55.5 \%)$ patients had anemia. Fifty-six (44.4\%) were males and $70(55.55 \%)$ were females. Among the anemic patients, $67(53.17 \%)$ had normal mean corpuscular volume (MCV), while 58 (46.03\%) had $\mathrm{MCV}<80 \mathrm{FL}$. while only one patient $(0.7 \%)$ had MVC >100 FL.

\section{The Effect of diabetic kidney disease}

Of the total 227 patients with diabetes, 91 (40.1\%) patients had GFR $>90 \mathrm{~mL} / \mathrm{min} / 1.73 \mathrm{~m}^{2}$ While 136 (59.9\%) patients had GFR $<90$ $\mathrm{mL} / \mathrm{min} / 1.73 \mathrm{~m}^{2}$ (Figure 1). Amongst patients with impaired kidney function, 88 (64.7\%) had anemia while 48 (35.3\%) had no anemia (chisquare $11.76, \mathrm{P}<0.05)$.

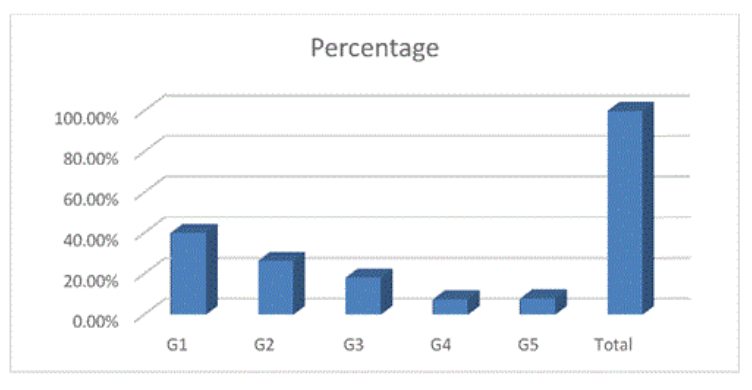

G : Stage of chronic kidney disease.

Figure 1: Distributions of total sample over the stages of chronic kidney disease. Of the total 227 patients with diabetes, $40.1 \%$ had GFR $>90 \mathrm{~mL} / \mathrm{min} / 1.73 \mathrm{~m}^{2}$, While the remaining $59.9 \%$ are distributed over the other stages of chronic kidney disease.

\section{Effect on vascular complications}

Diabetic patient with anemia were found to have heart disease (62\%) compared with patients without anemia (38\%) (Chi-square 14.44, P-value $<0.05)$. Twenty-two diabetic patients with anemia (64.7\%) had stroke compared with $12(35.3 \%)$ patients without anemia (chi-square $8.47, \mathrm{P}$-value $<0.05$ ). Out of 138 diabetic patients with hypertension, $82(59.4 \%)$ patients were anemic as compared to 56 $(40.6 \%)$ patients who were non-anemic. $(2,138, \mathrm{P}$-value<0.05) (Figure 2).

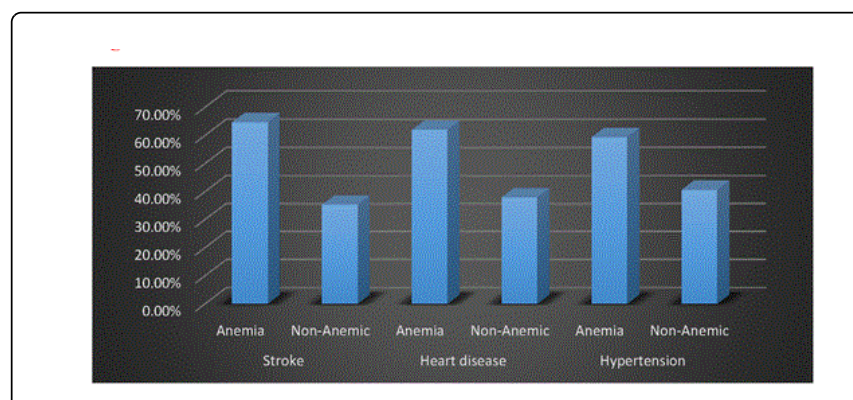

Figure 2: Distribution of vascular complications with respect to anemia. Diabetic patient with anemia found to have vascular complications more as compared with patients without anemia (Pvalue $<0.05$ ). 
Page 3 of 4

\section{Discussion}

Anemia is common in diabetes, potentially contributing to the pathogenesis of diabetes complications [15]. The prevalence of anemia in our study population is $55.5 \%$, which is two to three times more common as compared to the result from previous studies (19-25\%) $[5,16]$. Approximately one in two patients $(126 / 227)$ had anemia as defined by gender-specific WHO guidelines.

Prevalence of anemia in patients with diabetes correlated with renal impairment. The percentage of anemic patient with $\mathrm{GFR}<60 \mathrm{~mL} / \mathrm{min} /$ $1.73 \mathrm{~m}^{2}(46 \%)$ which is comparable to the result from other study (36\%) [5]. However, it is about two time more when compared to nonanemic patient in the same stages $(17.8 \%)$ and this is may be explained that anemia increase the progression of renal impairment as compared to those without anemia who are allocated in the early stages of kidney disease (Figure 3). Although anemia in diabetic patient correlated with degree of renal impairment, in our study anemia was six times more common (53.9\%), compared to the previous study (9\%) for the same GFR value $\left(\mathrm{GFR}>60 \mathrm{~mL} / \mathrm{min} / 1.73 \mathrm{~m}^{2}\right.$ ) and half of them in stage one kidney disease unlike in previous study $[5,16,17]$. Despite the predominance of patients with anemia in the early stages of chronic kidney disease, their numbers are progressively decreasing with progression of kidney disease and this may be explained by increased morbidity and mortality as anemia closely associated with vascular complications.

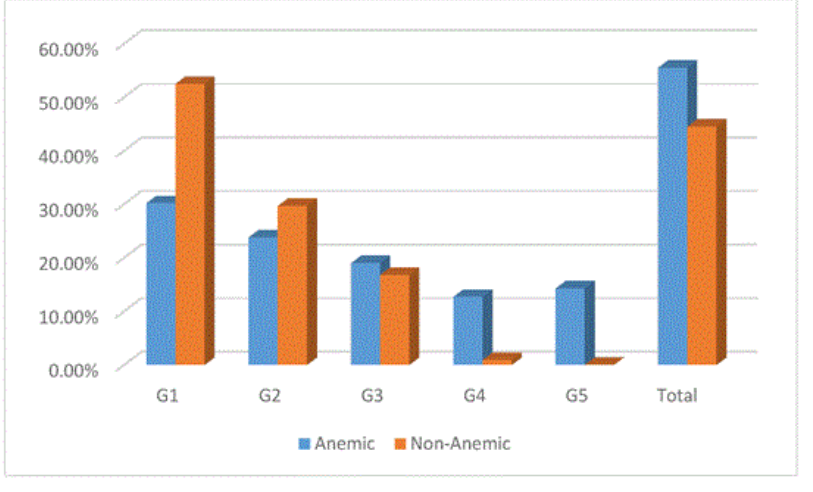

Figure 3: Distributions of anemic and non-anemic patient over the stages of chronic kidney disease. The percentage of anemic patient with GFR $<60 \mathrm{~mL} / \mathrm{min} / 1.73 \mathrm{~m}^{2}$ (46\%) which is about two time more when compared to non-anemic patient in the same stages (17.8\%)

Though the current recommendations for screening for anemia in the UK, target patients with stage $3 \mathrm{CKD}(\mathrm{eGFR}<60 \mathrm{ml} / \mathrm{min}$ per 1.73 $\mathrm{m}^{2}$ ), In our study it would fail to detect $53.9 \%$ of patients with diabetes and anemia with who have an EGFR $>60 \mathrm{~m} / \mathrm{min}$ per $1.73 \mathrm{~m}^{2}$ [5]. So, ideally our patients with diabetes should be screened for anemia from the onset of diabetes.

Our study has several limitations. First, although the prevalence of anemia is high as compared to the previous studies, the main etiology for anemia was not investigated which is very crucial, as hemoglobinopathies are quite common in Saudi Arabia and the variation of measured prevalence depends on the population studied and definition used [18]. Secondly, the interval between the diagnosis of diabetes and the onset of anemia was not known in this retrospective study. Therefore, the ideal timing for anemia screening remains unclear or vague.

\section{Conclusion}

Anemia is a common accompaniment with diabetes and it is seen early even in the absence of renal impairment. So, it may have further role in the development and progression of both micro and macrovascular complications.

\section{Acknowledgement}

I am grateful to primary health care center of King Faisal University for their support by using patients clinical and laboratory data. I would also like to extend my appreciation to study participants for providing necessary information for this study.

\section{References}

1. Guariguata L, Whiting DR, Hambleton I, Beagley J , Linnenkamp U, et al. (2014) Global estimates of diabetes prevalence for 2013 and projections for 2035. Diabetes Res Clin Pract 103: 137-149.

2. Wright JA, Oddy MJ, Richards T (2014) Presence and characterization of anaemia in diabetic foot ulceration. Anemia 2014: 104214

3. Abate1 A, Birhan W, Alemu A (2013) Association of anemia and renal function test among diabetes mellitus patients attending Fenote Selam Hospital, West Gojam, Northwest Ethiopia: a cross sectional study. BMC Hematol 13:6.

4. Thomas MC, Cooper ME, Rossing K, Parving HH (2006) Anaemia in diabetes: is there a rationale to TREAT? Diabetologia 49: 1151-1157.

5. Jones SC, Smith D, Nag S, Bilous MT, Winship S, et al. (2010) Prevalence and nature of anaemia in a prospective, population-based sample of people with diabetes: teesside anaemia in diabetes (TAD) study. Diabet Med 27: 655-659.

6. Shokoufeh B, Mohammad V, Mohammad G (2011) The prevalence of anemia in Iranian type two diabetic patients and the role of nephropathy. Saudi J Kidney Dis Transpl 22: 286-290.

7. El-Achkar TM, Ohmit SE, McCullough PA, Crook ED, Brown WW, et al. (2005) Higher prevalence of anemia with diabetes mellitus in moderate kidney insufficiency: The Kidney Early Evaluation Program. Kidney Int 67: 1483-1488.

8. New JP, Aung T, Baker PG, Yong sheng G, Pylypczuk R, et al. (2008) The high prevalence of unrecognized anaemia in patients with diabetes and chronic kidney disease: a population-based study. Diabet Med 25: 564569.

9. American Diabetes Association (2010) Diagnosis and classification of diabetes. Diabetes care 33: S62-S69.

10. Beulter E, Waalen J (2006) The definition of anemia: what is the lower limit of normal of the blood hemoglobin concentration? Blood 107: 1747-50.

11. Lam AP, Gundabolu K, Sridharan A, Jain R, Msaouel P, et al. (2013) Multiplicative interaction between mean corpuscular volume and red cell distribution width in predicting mortality of elderly patients with and without anemia. Am J Hematol. 88: E24.

12. Isakov E, Froom P, Henig C, Barak M (2014) Anemia and estimated glomerular filtration rates. Ann Clin Lab Sci. 44: 419-424.

13. Liu X, Qiu X, Shi C, Huang H, Huang J, et al. (2014) Modified Glomerular Filtration Rate-Estimating Equations Developed in Asiatic Population for Chinese Patients with Type 2 Diabetes. Int J Endocrinol 9.

14. Levey AS, Eckardt KU, Tsukamoto Y, Levin A, Coresh J, et al. Definition and classification of chronic kidney disease: a position statement from Kidney Disease: Improving Global Outcomes (KDIGO). Kidney Int 67: 2089-2100. 
Citation: Salman MA (2015) Anemia in Patients with Diabetes Mellitus: Prevalence and Progression. General Med 3: 1000162. doi: $10.4172 / 2327-5146.1000162$

Page 4 of 4

15. Thomas MC, MacIsaac RJ, Tsalamandris C, Molyneaux L, Goubina I, et al. (2004) The burden of anaemia in type 2 diabetes and the role of nephropathy: a cross sectional audit. Nephrol Dial Transplant 19: 17921797.

16. Merlin CT, Richard JM, Con T, Lynda M, Inna G, et al. (2004) Anemia in patients with type 1 diabetes. J Clin Endocrinol Metab 89: 4359-4363.
17. Thomas MC (2007) Anemia in diabetes: marker or mediator of microvascular disease? Nat Clin Pract Nephrol 3: 20-30.

18. Alsaeed AH (2012) Prevalence of hemoglobinopathy disorders in adult patients sent for diagnosis of anemia in Saudi Arabia. Genet Test Mol Biomarkers 16: 25-29. 